ORIGINAL ARTICLE

\title{
SENSORY INTEGRATION VERSUS COGNITIVE- BEHAVIORAL THERAPY ON BEHAVIORAL ISSUES IN LEARNING-DISABLED CHILDREN
}

\begin{abstract}
\section{BACKGROUND AND AIMS}

Number of studies demonstrated that children with learning disabilities suffers from emotional-behavioral problems, however neurophysiologic approaches are efficient to produce better health-related outcomes thus this study aimed to investigate the effectiveness of sensory integration versus cognitive-behavioral therapy on behavioral issues of learning-disabled children.
\end{abstract}

\section{METHODOLOGY}

A Randomized Controlled Trial included 30 learning disabled-children, diagnosed by Psychologist on the standardized criteria, divided into Group-A $(n=15)$ and B $(n=15)$ where Group-A performed Sensory Integration while B performed Cognitive-Behavioral Therapy for 4 weeks. Data was collected at baseline and post the intervention on Behavioral Problem Scale and Conner's Teacher Rating Scale respectively.

\section{RESULTS}

Both the groups showed significant results ( $\mathrm{p}<0.05)$, however Group-A showed marked reduction in BPS in comparison to B while CTRS was observed with slight greater improvement in Group-B than A.

\section{CONCLUSION}

It was concluded that sensory integration is as effective as cognitive behavioral therapy in improving behavioral problems of learning-disabled children.

\section{KEYWORDS}

Learning, Behavior, Children, Cognitive-Function, Disability Evaluation, Rehabilitation.
Ms.Syeda Iffat Nasir

Rehabilitation Program Advisor Policy and Planning Division

Ministry of Transportation, Ontario szehra07@yahoo.com

[Nasir SI, Sensory Integration versus Cognitive-Behavioral Therapy on Behavioral Issues in Learning-Disabled Children.Pak.j.rehabil.2020;11-17] DOI:10.36283/pjr.zu.9.2/004 


\section{INTRODUCTION}

According to a study the Learning disability affect 1.5 million people worldwide and it is the most prevailing form of disability'. Another literature search identified, 3 out of 100 individuals were annually affected with this form ${ }^{2}$. It is also known as dyslexia, dyscalculia, dyspraxia etc. that is problems in learning, articulating phonemes and in mathematical concepts $2.5 \%$ of students who are studying in public schools have been affected with Learning disability ${ }^{3}$.It is not occurred alone, but it is the mixture of many symptoms like, speech errors calculations, and reading difficulties ${ }^{3,4}$. These learning difficulties in children can identified in conjunction with other, or with several emotional, social and behavioral disabilities ${ }^{5}$.Learning disability affects the variety of functional skills like read, write, speak and listen etc. Furthermore, the ability to receive and retrieve information is idiopathic. Another study by, Boardman et al (2018) indicated these children have higher IQ regardless of their disability ${ }^{3,4}$. Numerous studies identified that conditions of learning difficulties also affect many brain areas which leads to devastating consequences. Even though, at a time an individual can exhibited from more than one learning disability ${ }^{5,6}$. In 2005, Lerner explain nine characteristics of learning disabled individuals in which it can occur naming; problem with processing of information, deficits of psychological processes, quantitative problems, impaired social skills, difficulties in oral language, problem with written language, compromised motor skills, reading difficulties, and difficulty in sustaining attention ${ }^{7}$. As per literature, it was revealed that the most common form of learning disability is reading disorder and presented in individual consist of 70 to $80 \%$ learning deficits in reading activity ${ }^{7}$.Children with learning deficits, exhibits difficulties in phonemic awareness which is ability to segmented sounds while difficulty with the letters with matched combinations with respect to sound-symbol correspondence. However, grammatical punctuation and spelling errors as well as poor penmanship exhibited with written expression ${ }^{8}$. Non-verbal disability can evident comprising of clumsiness in motor activity, poor visual acuity, organization manner and social problems are different from reading difficulty 9.10 . In many studies it has been proved that children with learning disability may experience from variety of social, emotional and behavioral problems that may vary from mild to severe in heterogeneous group ". Moreover, behavioral features included attention deficits, difficulty in pragmatic language, poor social skills, quantitative disorders as well as information processing disability are common in children suffering from the condition ${ }^{12,13}$. In some researches it is revealed that only $5 \%$ prevalence rate of learning disability is identified while rest is unknown. Besides, Ruppar et al (2015) and Ciullo, Falcomata and Vaughn (2015) revealed that the most common difficulties which are faced by children with learning disabilities, in particular dyslexia, dyscalculia and combination of it ${ }^{13,14}$. It was exposed that these were common conditions among primary school children with higher prevalence rate. It was also reflected in the study that comparison among those results similar levels of neural activation in the brain with unidentified pattern. Furthermore, it was also observed that not only the brain activity is similar, the behavioral presentation among these children may also be similar ${ }^{15,16,17}$. It was also revealed in the same studies that children with learning disability have disturbed relationship with peers and family. These unfulfilled needs tend to generate avoidance behavior that makes it more difficult for these children to understand social cues. These children adopt different defensive behaviors to avoid social relationships. Some of them may even practice aggressive and irritable behavior as coping technique ${ }^{18}$. Researchers recommend that whenever learning disabilities occurs with the combination of behavioral disorder, then it should be important to recognize the root cause of this association ${ }^{19}$. In one study which is conducted in Belgium explained the relationship between learning disabilities and emotional-behavioral problems. This study highlights these emotional-behavioral problems such as difficulty to make and maintain friendships and poor social skills. Moreover, these emotional- behavioral problems may results poor communication skills, so they become more egocentric nature ${ }^{20}$.

According to one more study on learning disability revealed that most of the students have difficulty in solving word problems so they rarely are successful in accomplishment of it ${ }^{21}$. Moreover, with the help of learning disability scale, it was indicated that these children have fidgety problems, aggressive and hyperactive behavior, delinquent tendencies, as well as several phobias and sleep disturbances under the umbrella of emotional and behavioral problems ${ }^{22}$ although, the frequency may differ in emotional and behavioral problems because of type of disability ${ }^{23,24}$. Moreover, McConaughy et al explained that those children who have difficulty in attention are among the best to predict learning disabilities. Furthermore, they also recommend that children who have faced learning disabilities may also experience social and emotional affects. In addition, this study also indicated the chief reported patterns that are, fidgeting, aggressive and hyperactive states sleep disturbances, phobias, and poor social skills ${ }^{25}$. In particular, there is a strong connection between learning disability and psychopathology as well. In another study, conducted by Cantwell and Baker, 600 speech and language impaired children were recruited and followed for 5 years, resulted that only $25 \%$ of these children had learning disability while rest of the $75 \%$ children had psychiatric illness. Anxiety and depres- 
sion are the most common presentation in these children ${ }^{26}$. Similarly, in one study it was observed that behavioral and emotional imbalance in child life may result poor academic achievement and difficulty in social development. The primary care givers and guardians are the first ones who noticed and identified these problems and seek treatment for their child. Previous researches highlighted the different factors that affect a child's learning ability, but the social, emotional, and behavioral difficulties have remained unidentified ${ }^{27}$.

Despite of the fact, certain neurophysiologic interventions are found to effective in improving behavioral problems as it has been evident that management with medication has found to be most cost-effective yet individual behavioral, sensory or combined neurophysiologic approach has also shown effectiveness ${ }^{28,29}$. However, these approaches are only limited to certain population such that ADHD, Cerebral Palsy or Autism. Therefore, to the best of author's knowledge, no or limited sensory or behavioral interventions have been conducted on learning-disabled children. Besides, very few studies have been conducted in Pakistan, to uncover the behavioral and emotional problems in children with learning disabilities. This may be because of low resources and shortage of data. So, the aim of this study is investigate the effectiveness of sensory integration versus cognitive-behavioral therapy on behavioral issues of learning-disabled children and to provide a guide to future studies to identify methods to overcome this devastating cause. Further, to provide awareness of the factors related to the learning disability.

\section{METHODOLOGY}

\section{STUDY DESIGN}

Randomized Controlled Trial

\section{STUDY SETTING AND PARTICIPANTS}

The study was conducted at DEWA Learning Disability School on the children with mild to moderate learning disability.

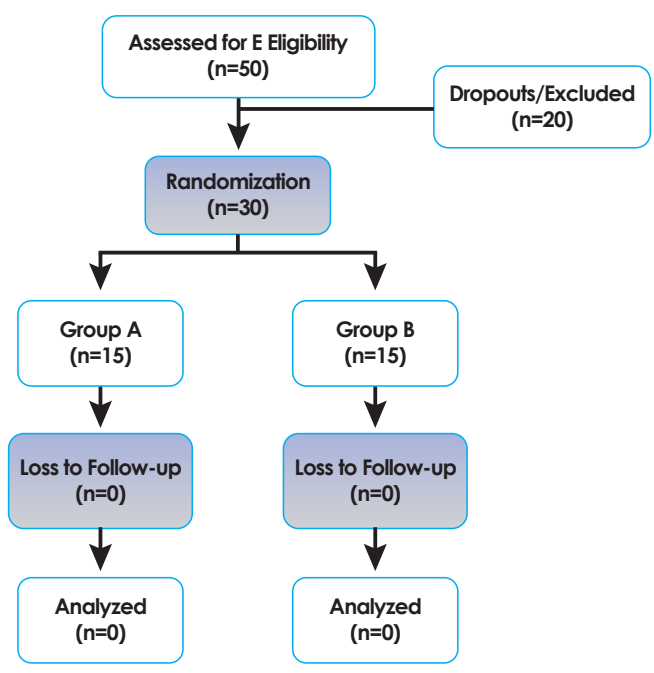

\section{DURATION OF STUDY}

Study was completed within the duration of six months.

\section{SAMPLE SIZE}

A total sample of 30 participants was recruited in the study.

\section{SAMPLING TECHNIQUE}

The participants were allocated into Group-A $(n=15)$ and $B \quad(n=15)$ through computer-based randomization .

\section{SAMPLE SELECTION - INCLUSION CRITERIA}

Learning-Disabled children aged 6 to 12 years, diagnosed by Psychologist through IQ level and Standardized Achievements i.e. Reading, Writing or Arithmetic tests. The children were also not indulging in either type of physical, occupational or psychological therapy.

\section{- EXCLUSION CRITERIA}

Primary Caregiver/participant's' refusal to participate in the intervention or children with severe learning disabilities or have secondary complications.

\section{DATA COLLECTION TOOL}

- Behavioral Problem Scale (BPS) comprised of 18 questions related to behavior. The 5-point likert scale was used to record the response of each participant. The scale is ranging from 1-5, where 1 denotes never, 2 denotes seldom, 3 denotes sometimes, 4 denotes always, and 5 denotes very often. Highest score was 4 and 5.

- Conner's Teacher Rating Scale (CTRS) consisted of 30 questions, based on the number of common problems associated with behavior in the last month on 5-likert rating scale of Never Seldom, Occasionally, Often, Very Often and Not Ticked.

\section{INTERVENTION \\ - GROUP-A}

The participants of Group-A performed Sensory Integration Therapy, 1 hour session, 3 days per week for 4 weeks. The 12 sessions of therapy included number of stimulus such as brushing (Tactile), jumping on trampoline, bouncing, push-pull activities (Proprioception), sing-songs (Auditory) swinging, rolling, spinning (Vestibular) and focusing or following pathways (Visual).

\begin{tabular}{|c|c|c|}
\hline & 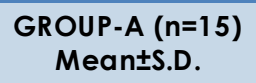 & $\begin{array}{c}\text { GROUP-B }(n=15) \\
\text { Mean } \pm \text { S.D. }\end{array}$ \\
\hline Age (years) & $11.78 \pm 1.6$ & $10.33 \pm 1.2$ \\
\hline Gender & $\begin{array}{c}6 \text { Males } \\
9 \text { Females }\end{array}$ & $\begin{array}{l}5 \text { Males } \\
10 \text { Females }\end{array}$ \\
\hline Height & $85.6 \pm 9.3$ & $71.1 \pm 8.8$ \\
\hline Weight & $12.3 \pm 5.4$ & $11.9 \pm 4.3$ \\
\hline
\end{tabular}




\section{- GROUP-B}

The participants performed time-matched Cognitive-Behavioral Therapy that included problem-solving approach with game and activities along with self-instruction training that will guide the child's cognition and overt behaviors. These components were taught to the child to resolve their social problems.

\section{DATA ANALYSIS STRATEGIES}

Data was entered and analyzed on IBM SPSS Statistics version 20 . The frequency and standard deviations of the demographic data was determine through descriptive statistics while paired t-test and independent t-test were applied as an inferential statistics within and in between the groups respectively.

\section{RESULTS}

A total number of 30 participants completed the intervention with mean age of $11.78 \pm 1.6$ in Group-A with 6 males and 9 females whereas 5 males and 10 females in Group B with mean age of 10.33 \pm 1.2 . The baseline characteristics of participants are shown in Table-1.

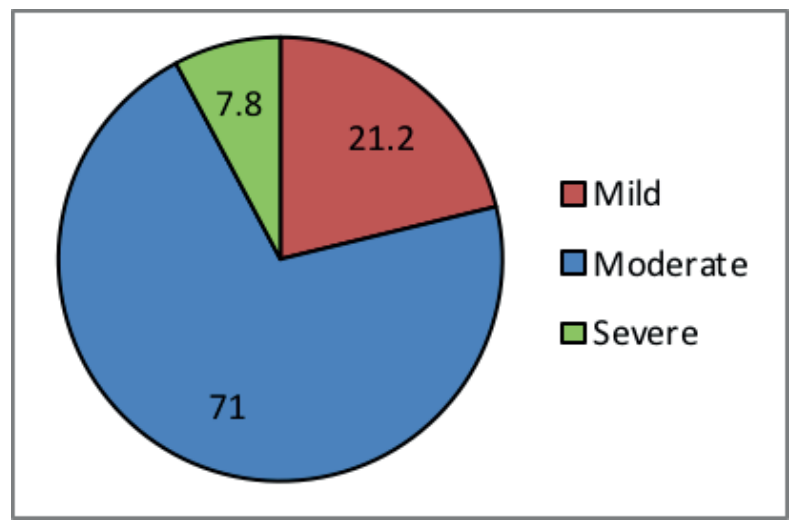

Figure.1 represents categories of participant's behavior on BPS

In within the group, paired t-test analysis, Group-A and $B$ showed significant improvements in BPS and CTRS $(p<0.05)$ however, Group-A showed more improvement in BPS in comparison to B while Group-B demonstrated slightly greater improvement in CTRS as shown in Table.2.

\begin{tabular}{|c|c|c|c|}
\hline \multicolumn{4}{|c|}{ Table.2 Within the Group Analysis of Group-A and B } \\
\hline $\begin{array}{c}\text { Outcome } \\
\text { Measures }\end{array}$ & & Group-A & Group-B \\
\hline \multirow{2}{*}{ BPS } & Pre & $43.21 \pm 9.7$ & $42.24 \pm 7.6$ \\
\cline { 2 - 4 } & Post & $48.39 \pm 10.7^{*}$ & $46.32 \pm 9.8^{*}$ \\
\hline \multirow{2}{*}{ CTRS } & Pre & $29.21 \pm 5.8$ & $30.21 \pm 9.7$ \\
\cline { 2 - 4 } & Post & $32.39 \pm 10.7^{*}$ & $33.95 \pm 11.6^{*}$ \\
\hline${ }^{*} \mathbf{p}<0.05$ & \multicolumn{3}{|c}{} \\
\hline
\end{tabular}

Moreover, difference between Group-A and B was determined through Independent T-test after 4 weeks of intervention. The differences between the two groups were analyzed using post mean values of components. In general, both the groups showed significant results $(\mathrm{p}<0.05)$, however Group-A showed marked reduction in BPS in comparison to B while CTRS was observed with slight greater improvement in Group-B than A as shown in Figure-2.

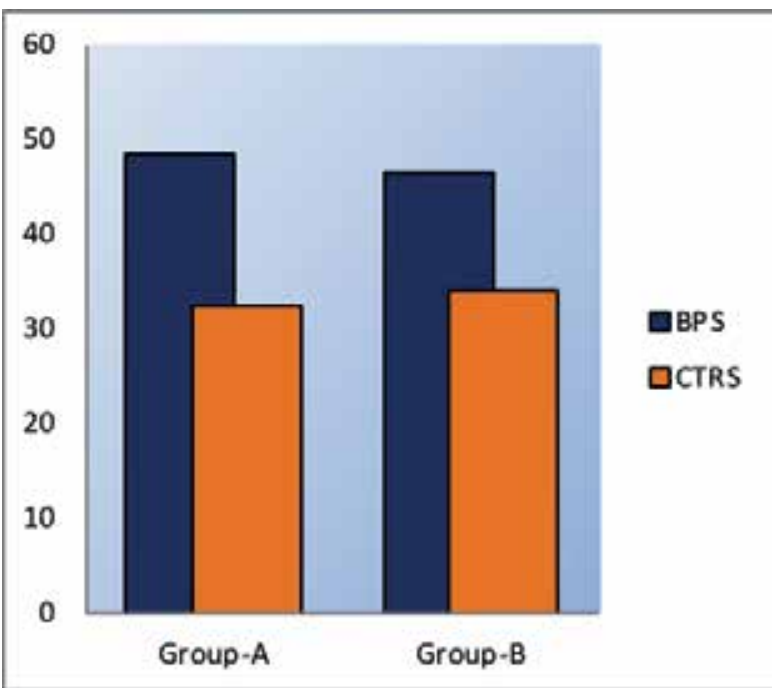

Figure. 2 shows post-mean values comparison of Group-A and B

\section{DISCUSSION}

The purpose of this study was to compare the effectiveness of sensory integration therapy and cognitive behavior therapy in learning disable children behavior. The implication may justify the efficacy of both the interventions on the target population. Furthermore, it was also revealed that mild behavioral problems exist in children with learning disabilities. It has been evident that higher the scores on BPS, higher problems were found in behavior. Recent literature endorsed that behavior problems may also lead towards psychiatric illness; therefore, early diagnosis might be helpful for the child for better health outcome $30,22,23$. To tap behavioral features, standardized instruments with excellent psychometric properties are needed. Availability of these resources is found to be limited. Studies also showed that intellectual disability is also a causative factor of behavioral issues that are mostly not addressed by the health care providers, if addressed then requires expensive healthcare facility for the confirmation of diagnosis ${ }^{31,24}$. Similarly, our study participants represent varied behaviors and emotions although due to limited sample size our study was not able to analyze the magnitude of the condition.

Recent literature recommends that specific educational instructions are required for social and emo- 
tional support that might help students in academic learning ${ }^{32,25}$. Moreover, it will provide sense of belongingness to students therefore they would not feel excluded. Another study by Sadusky et al (2018) revealed that affected children having peers with learning disability have greater rate of sharing and feel more positive regarding themselves ${ }^{33,26}$. In the similar study, it was also suggested that teacher's role is very important in this regard, teacher of the classroom must appreciate the positive behavior of acceptance and encouragement so in that way leading to relief in the negative impact of learning disabilities $34,27,28,29$. Collaborative partnership with families and support should also be the part of this program. On the other hand, Barry et al (2015) explained that it has been need to use some worldwide contributions to increase social and emotional competencies so, in that way it can reduce behavioral problems not only in affected individual but in also with those who had high risk of developing these problems ${ }^{31,32,33,35}$. In one study it was indicated that with the help of behavioral interventions can treat the learning disabilities and other linked conditions also like sleep disturbances and restlessness ${ }^{35}$. Likewise, one more study proved that behavioral interventions like role play have strong effective results in treating these conditions in children with learning disability ${ }^{36,37}$. Results of this study indicated that relaxation training can be very useful technique to treat aggressive behavior, anxiety and restlessness in children with learning disabilities ${ }^{38,39}$.

Researches proved that all psychodynamic and psychotherapeutic strategies and antipsychotic drugs can be effective in treating behavioral problems in learning disabilities ${ }^{40}$. With reference to one study, drugs can also play important part in treating the behavioral problems that in turn affect learning. Among them the efficacy of zuclopenthixol has found to be promising ${ }^{37}$. On the contrary, other studies comments on the efficacy of antipsychotic medications that it has being neither beneficial nor harmful to treat behavioral problems ${ }^{38}$. In contrast to it, other studies claim psychodynamic approach; including cognitive behavioral therapy and humanistic centered approach were found to be promising in treatment of learning disabilities ${ }^{40}$. Despite of the fact, certain evidences are supporting to the sensory integration and also cognitive behavioral therapy that may led inference that both the interventions are equally effective in improving behavioral symptoms in children with learning disabilities although, due to scarcity of studies in this domain generalizability of results is doubtful.

As learning disability is strongly associated with poor academic performance thereby leading a conflictval and often unsatisfactory pattern of relationships with family members, peers and teachers as well as low self-esteem ${ }^{31,25}$. Consequently, to answer the question of optimal types, and frequency of intervention, head-to- head comparison in which participants are randomly assigned to receive different therapies are highly desirable.

However, there is a need for more researches with large sample size and with standardized tool to identify the behavioral problems in children with learning disabilities. Furthermore, there is need to investigate the effect of modified educational programs that may work in learning disabled children. In addition, it is recommended to include some behavioral and learning techniques in teachers training program so that they can understand and manage the student behavior effectively during classroom activity and guide them that how they can control their impulses and manage their disability.

\section{CONCLUSION}

It was concluded that sensory integration is as effective as cognitive behavioral therapy in improving behavioral problems of learning-disabled children. Further, majority of children have moderate behavioral problems. Thus, more studies are suggested to investigate the behavioral and emotional issues with larger sample size to address these problems to avoid devastating health outcomes in future generations.

\section{REFERENCES}

[1] Chadda RK. Global Burden of Mental Disorders: Meeting the Challenge. Annals of the National Academy of Medical Sciences (India). 2016:52(01):039-55.

[2] Flanagan DP, Alfonso VC, Costa M, Palma K, Leahy MA. Use of ability tests in the identification of specific learning disabilities within the context of an operational definition. 2018

[3] Peters L, Bulthé J, Daniels N, de Beeck HO, De Smedt B. Dyscalculia and dyslexia: Different behavioral, yet similar brain activity profiles during arithmetic. Neurolmage: Clinical. 2018 ;18:663-74.

[4] Boardman A, Vaughn S, Klingner J. Teaching Collaborative Strategic Reading (CSR) to Students with Learning Disabilities. From Floundering to Fluent: Reaching and Teaching Struggling Readers. 2018 8:83.

[5] Cheng D, Xiao Q, Chen Q, Cui J, Zhou X. Dyslexia and dyscalculia are characterized by common visual perception deficits. Developmental neuropsychology. 2018;43(6):497-507.

[6] Ulfarsson MO, Walters GB, Gustafsson O, Steinberg S, Silva A, Doyle OM, Brammer M, Gudbjartsson DF, Arnarsdottir S, Jonsdottir GA, Gisladottir RS. 15q11.2 CNV affects cognitive, structural and functional correlates of dyslexia and dyscalculia. Translational psychiatry. 2017;7(4):el109-.

[7] Kemp SE. RAP: A reading comprehension 
strategy for students with learning disabilities and concomitant speech-language impairments or ADHD.2017.

[8] Witzel B, Mize M. Meeting the Needs of Students with Dyslexia and Dyscalculia. SRATE journal. 2018;27(1):31-9.

[9] Loewenthal KM, Lewis CA. An introduction to psychological tests and scales. Psychology press; 2018.

[10] Boardman AG, Vaughn S, Buckley P, Reutebuch C, Roberts G, Klingner J. Collaborative strategic reading for students with learning disabilities in upper elementary classrooms. Exceptional Children. 2016;82(4):409-27.

[11] Rasheed T, Siddiqua A, Naureen S. Exploring Behavioral Problems and Psychological Adjustment of Special Children with Learning Disabilities. Journal of University Medical \& Dental College. 2016;7(3):60-3.

[12] Wong C, Odom SL, Hume KA, Cox AW, Fettig A, Kucharczyk S, Brock ME, Plavnick JB, Fleury VP, Schultz TR. Evidence-based practices for children, youth, and young adults with autism spectrum disorder: A comprehensive review. J. Autism Dev. Disord.. 2015;45(7):1951-66.

[13] Ruppar AL, Gaffney JS, Dymond SK. Influences on teachers' decisions about literacy for secondary students with severe disabilities. Exceptional Children. $2015 ; 81$ (2):209-26.

[14] Ciullo S, Falcomata T, Vaughn S. Teaching social studies to upper elementary students with learning disabilities: Graphic organizers and explicit instruction. Learning Disability Quarterly. 2015;38(1):15-26.

[15] Petchimuthu P, Sharma N, Gaur A, Kumar R. Pattern of specific learning disability and awareness among care providers in children between 8-12 years. Int J ContempPediatr. 2018:5:809-14.

[16] Shakouri M, Hashemi-Razini H. Is there any difference in executive function and social adequacy between the children with dyslexia or dyscalculia disorder?. Chronic Diseases Journal. 2019;7(3):214-8.

[17] Kucian K. The importance of central-visual perception disorders for dyslexia and dyscalculia. Neuropediatrics. 2017;48(S 01):KSS20-04.

[18] Franklin D. Helping your child with language-based learning disabilities: Strategies to succeed in school and life with dyslexia, dysgraphia, dyscalculia, ADHD, and processing disorders. New Harbinger Publications; 2018.

[19] Briscoe H, Ashworth S, Shelton L. Establishing the concurrent validity of the Clinical Outcome in Routine Evaluation-Learning Disabilities scale. Advances in Mental Health and Intellectual Disabilities. 2019.

[20] Kurth JA, Lyon KJ, Shogren KA. Supporting students with severe disabilities in inclusive schools: A descriptive account from schools implementing inclusive practices. Research and Practice for Persons with Severe Disabilities. 2015;40(4):261-74.

[21] OK MW, Kim MK, Kang EY, Bryant BR. How to find good apps: An evaluation rubric for instructional apps for teaching students with learning disabilities. Intervention in School and Clinic. 2016;51 (4):244-52

[22] Geiger EF, Brewster ME. Development and Evaluation of the Individuals With Learning Disabilities and/or Difficulties Perceived Discrimination Scale. The Counseling Psychologist. $2018 ; 46(6): 708-37$

[23] Giofrè D, Toffalini E, Altoè G, Cornoldi C. Intelligence measures as diagnostic tools for children with specific learning disabilities. Intelligence. 2017 61:140-5.

[24] Lunsky Y, De Oliveira C, Wilton A, Wodchis W. High health care costs among adults with intellectual and developmental disabilities: a population-based study. Journal of Intellectual Disability Research. 2019;63(2):124-37.

[25] Lombardi A, Murray C, Kowitt J. Social support and academic success for college students with disabilities: Do relationship types matter? Journal of Vocational Rehabilitation. 2016:44(1):1-3.

[26] Sadusky A, Freeman NC, Jacobs KE, Reupert AE. Preservice Psychology Training About (Specific) Learning Differences. The Educational and Developmental Psychologist. 2018 Dec;35(2):51-66.

[27] Cavioni V, Zanetti MA. Social-emotional learning and students' transition from kindergarten to primary school in Italy. In Early Childhood Development: Concepts, Methodologies, Tools, and Applications 2019 (pp. 528-547). IGI Global.

[28] Cefai C, Cavioni V. Parents as active partners in social and emotional learning at school. 2016.57-66.

[29] Taylor RD, Oberle E, Durlak JA, Weissberg RP. Promoting positive youth development through school-based social and emotional learning interventions: A meta-analysis of follow-up effects. Child development. 2017 ;88(4):1156-71.

[30] Barry MM, Clarke AM, Morreale SE, Field CA. A review of the evidence on the effects of community-based programs on young people's social and emotional skills development. Adolescent Research Review. 2018;3(1):13-27.

[31] Wang J, Mann F, Lloyd-Evans B, Ma R, Johnson S. Associations between loneliness and perceived social support and outcomes of mental health problems: a systematic review. BMC psychiatry. 2018 18(1):156.

[32] Rothman J. Social work practice across disability. Routledge; 2018.

[33] Slattery É, McMahon J, Gallagher S. Optimism and benefit finding in parents of children with developmental disabilities: The role of positive reappraisal and social support. Research in 
developmental disabilities. 2017;65:12-22.

[34] Hassan AE. Emotional and behavioral problems of children with learning disabilities (JEPER). 2015;2(10):66-74.

[35] Sutton JE, Huws JC, Burton CR. Experiences of sleep hygiene education as an intervention for sleep problems in children with developmental disabilities: Findings from an exploratory study. British Journal of Learning Disabilities. 2019:47(3):165-73.

[36] Suveg C, Jones A, Davis M, Jacob ML, Morelen D, Thomassin K, Whitehead M. Emotion-focused cognitive-behavioral therapy for youth with anxiety disorders: A randomized trial. Journal of Abnormal Child Psychology. 2018;46(3):569-80.

[37] Alexander RT, Shankar R, Cooper SA, Bhaumik
S, Hastings R, Kapugama CL, Tromans SJ, Roy A. Challenges and pitfalls of antipsychotic prescribing in people with learning disability. British Journal of General Practice. 2017;67(661):372-3.

[38] Adams D, Shah C. Prescribing of psychotropic medicines: The role of learning disability nurses. Learning Disability Practice. 2016;19(8).

[39] Bekirogullari Z. Cognitive Behavioural Therapy in Treating Persons with Learning Disabilities. Online Submission. 2018;8(2):31-9.

[40] Mclnnis EE. Critical literature review: effectiveness of individual psychodynamic psychotherapy for adults with intellectual disabilities. Advances in Mental Health and Intellectual Disabilities. 2016. 